\title{
Article \\ In Silico Investigation on the Interaction of Chiral Phytochemicals from Opuntia ficus-indica with SARS-CoV-2 Mpro
}

\author{
Caterina Vicidomini ${ }^{1,+}$, Valentina Roviello ${ }^{2,+}$ and Giovanni N. Roviello ${ }^{1, *(D)}$ \\ 1 Istituto di Biostrutture e Bioimmagini IBB-CNR, Mezzocannone Site and Headquarters, I-80134 Naples, Italy; \\ caterina.vicidomini@ibb.cnr.it \\ 2 Department of Chemical, Materials and Industrial Production Engineering (DICMaPI), University of Naples \\ Federico II, Piazzale V. Tecchio 80, 80125 Naples, Italy; valentina.roviello@unina.it \\ * Correspondence: giroviel@unina.it or giovanni.roviello@cnr.it \\ + These authors contributed equally.
}

Citation: Vicidomini, C.; Roviello, V.; Roviello, G.N. In Silico Investigation on the Interaction of Chiral Phytochemicals from Opuntia ficus-indica with SARS-CoV-2 Mpro. Symmetry 2021, 13, 1041. https:// doi.org/10.3390/sym13061041

Academic Editor: Oleg A. Zadvornyy

Received: 21 April 2021

Accepted: 7 June 2021

Published: 9 June 2021

Publisher's Note: MDPI stays neutral with regard to jurisdictional claims in published maps and institutional affiliations.

Copyright: (c) 2021 by the authors. Licensee MDPI, Basel, Switzerland. This article is an open access article distributed under the terms and conditions of the Creative Commons Attribution (CC BY) license (https:// creativecommons.org/licenses/by/ $4.0 /)$.

\begin{abstract}
Opuntia ficus-indica is a cactaceous plant native to America but, nowadays, widely found worldwide, having been the most common domesticated species of cactus grown as a crop plant in semiarid and arid parts of the globe, including several Mediterranean basin countries. Opuntia ficus-indica can be regarded as a medicinal plant, being source of numerous bioactive phytochemicals such as vitamins, polyphenols, and amino acids. The urgent need for therapeutic treatments for the COronaVIrus Disease 19 (COVID-19), caused by the Severe Acute Respiratory Syndrome (SARS)Coronavirus (CoV)-2, justifies the great attention currently being paid not only to repurposed antiviral drugs, but also to natural products and herbal medications. In this context, the anti-COVID-19 utility of Opuntia ficus-indica as source of potential antiviral drugs was investigated in this work on the basis of the activity of some of its phytochemical constituents. The antiviral potential was evaluated in silico in docking experiments with $\mathrm{M}^{\text {pro }}$, i.e., the main protease of SARS-CoV-2, that is one of the most investigated protein targets of therapeutic strategies for COVID-19. By using two webbased molecular docking programs (1-Click Mcule and COVID-19 Docking Server), we found, for several flavonols and flavonol glucosides isolated from Opuntia ficus-indica, good binding affinities for $\mathrm{M}^{\text {pro }}$, and in particular, binding energies lower than $-7.0 \mathrm{kcal} / \mathrm{mol}$ were predicted for astragalin, isorhamnetin, isorhamnetin 3-O-glucoside, 3-O-caffeoyl quinic acid, and quercetin 5,4'-dimethyl ether. Among these compounds, the chiral compound astragalin showed in our in silico studies the highest affinity for $\mathrm{M}^{\text {pro }}(-8.7 \mathrm{kcal} / \mathrm{mol})$ and also a low toxicity profile, emerging, thus, as an interesting protease inhibitor candidate for anti-COVID-19 strategies.
\end{abstract}

Keywords: plant drugs; Opuntia ficus-indica; SARS-CoV-2; COVID-19; docking; energy minimization; pandemic; therapeutic

\section{Introduction}

Opuntia ficus-indica, also known as Indian fig and nopal cactus [1], is a dicotyledonous angiosperm cactaceous plant widespread worldwide in tropical and subtropical regions, including those surrounding the Mediterranean sea, with semi-arid and arid climates [2]. Recently, Opuntia ficus-indica's nutritional and health benefits have been suggested due to its phytochemical composition particularly rich in polyphenols, which are the main compounds responsible for antioxidant properties of plant extracts [3], but also in vitamins and amino acids [3-6]. Opuntia ficus-indica is a fast-growing and productive plant [7,8] with potential utility in biogas [9] and biofuel [10] production, rehabilitation of degraded soils, and desertification/climate change mitigation, with important consequent environmental benefits [11-13]. Fruits and cladodes are widely used for human nutrition [14-16], with the latter also largely being used as livestock forage in South America and Africa [17,18]. 
Owing to the biomedically-relevant properties of Opuntia cactuses, it is worth mentioning that several plant extracts and Opuntia-isolated compounds are endowed with antimicrobial, antioxidant, anti-inflammatory, antidiabetic, neuroprotective [3,19-29], and antiviral $[30,31]$ properties. Not less importantly, some phytochemicals isolated from nopal cactus waste peels showed anti-pneumonia properties [32]. In particular, the Opuntiaderived compounds extracted in ethyl acetate phase included astragalin, isorhamnetin, isorhamnetin-3-O-glucoside, and quercetin 5,4'-dimethyl ether, with the latter exerting the most relevant activity against the pneumonia pathogen investigated [32].

Three deadly RNA viruses of the family of Coronaviridae have emerged in the last eighteen years: SARS-CoV-1 (also known simply as SARS-CoV), MERS-CoV, and SARS$\mathrm{CoV}-2$. These coronaviruses ( $\mathrm{CoVs}$ ) can cause severe pneumonia in infected patients that can be lethal in several cases. SARS-CoV-2 is causing the current pandemic of COronaVIrus Disease 19 (COVID-19) which has provoked enormous sanitary as well social and economic impacts on the globe [33]. Prophylactic [34] and therapeutic strategies are currently under investigation worldwide, and among the latter, old antiviral drug repurposing $[35,36]$ is one of the main ways to respond to the urgency of an effective anti-COVID-19 therapy. Drug repurposing, in fact, involves drugs already known and in use for other pathologies and for which safety has already been assessed previously [35]. Similarly, plant extracts or isolated compounds already used as dietary supplements or ingredients of traditional medicine are attracting much interest in the therapy of SARS-CoV-2 [37,38].

In this context, considering the previously ascertained utility of Opuntia ficus-indica plant extracts or isolated compounds as antiviral and anti-pneumonia agents, the potential of some of the same identified molecules was tested in the present in silico study as inhibitors of Mpro (Figure 1). In fact, the main protease of SARS-CoV-2 represents one of the most attractive targets for COVID-19 drug development due to the absence of this type of proteins in humans and its essential role in viral replication [39].

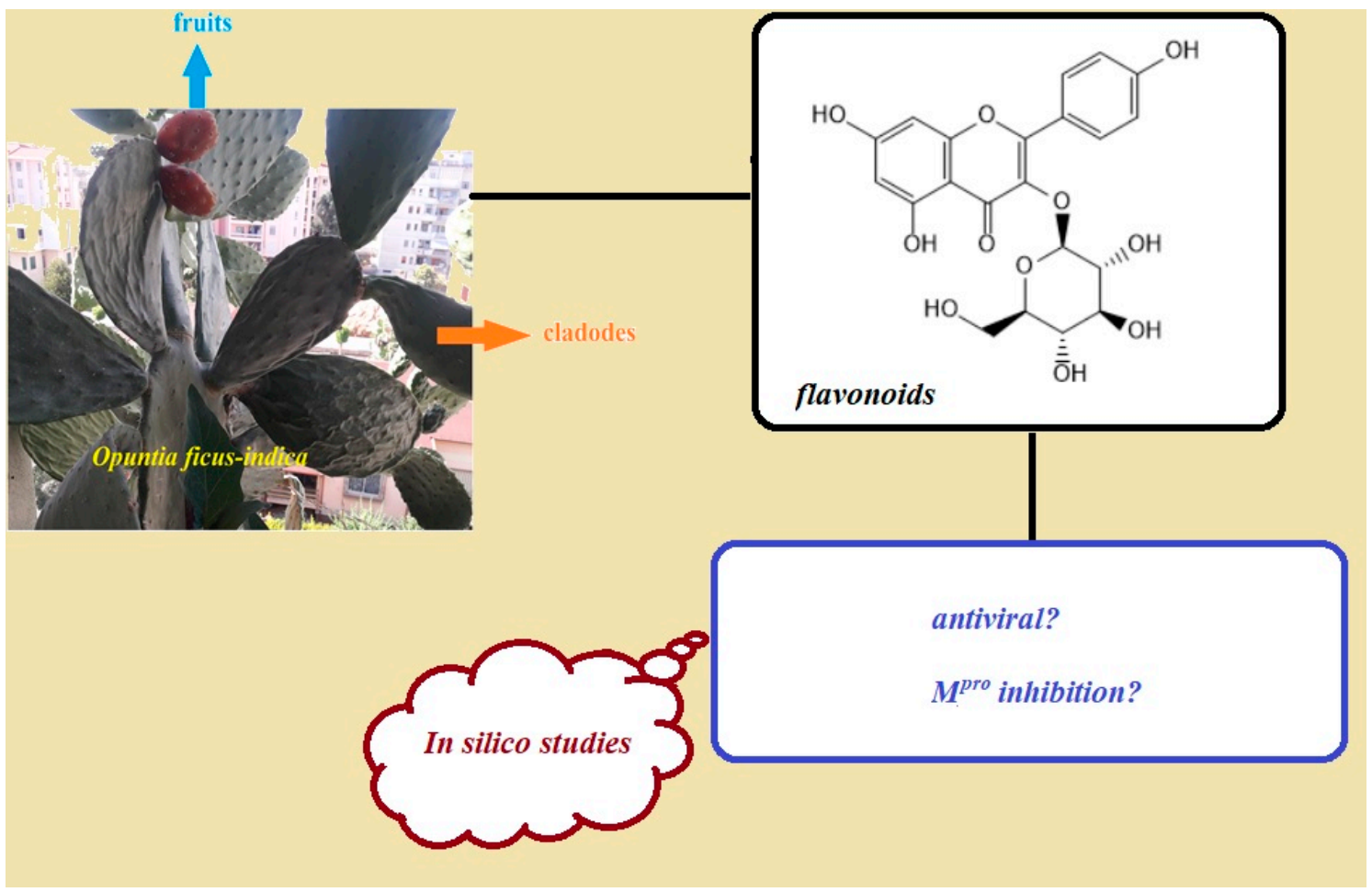

Figure 1. Photograph of Opuntia ficus-indica (fruits and cladodes, photograph taken by G. Roviello in Aversa, Italy) and schematic representation of the main strategy of the present study: literature data analysis and selection of Opuntia phytochemicals, followed by their computational evaluation as potential anti-COVID-19 drugs using M ${ }^{\text {pro }}$ as SARS-CoV-2 protein target. 


\section{Methods}

\subsection{Molecular Docking Studies}

For the computational studies, we used the 3D structure of $\mathrm{M}^{\text {pro }}$ with an unliganded active site (PDB ID: 6Y84), downloaded from the Protein Data Bank [40]. The structures for the natural compounds (Figure 2) investigated as protease ligands were retrieved by us from the PubChem database (https: / / pubchem.ncbi.nlm.nih.gov/, all links mentioned in this work were accessed on 11 December 2020), whilst those not present in PubChem were drawn with the molecular editor of 1-Click Mcule (Mcule Inc., Palo Alto, CA, USA) [41-44], an online docking platform making use of AutoDock Vina [45], by which the docking experiments herein described were performed. For the molecular dockings, we used, as atomic coordinates of the binding site, X: 9.204, Y: -4.557 , and Z: 19.602, which were previously reported in the literature for the binding center [46], and we set the size of the binding site as 22 Angstrom. The docking poses with the most negative docking scores $(\mathrm{kcal} / \mathrm{mol})$, corresponding to the highest binding affinities, were selected for further analysis (Table 1). To validate the docking method, we applied it to other literature dockings having $\mathrm{M}^{\text {pro }}$ as a protein target [47], and used the N3 inhibitor as a reference compound (Figure 2), finding that the resulting scores were in line with those previously reported for ligands like the phenolic diterpene carnosol [46], bictegravir, and other molecules docked to the same protease [48]. We made use of the molecular graphics program embedded in 1-Clik Mcule for structural visualization of protein-ligand complexes and to obtain the snapshots of Figure 3A,B, while we obtained the protein-ligand interaction diagrams reported in the same figure (Figure 3C,D) and in Figure 4 by ProteinsPlus (https: / / proteins.plus /) or PLIP (Protein-Ligand Interaction Profiler, https:/ / plip-tool.biotec.tu-dresden.de/) [49,50]. For the N3 inhibitor/astragalin-bound $\mathrm{M}^{\text {pro }}$ structural comparison (Figure 3E), we made use of the matchmaker tool embedded in UCSF Chimera [51]. To this scope, we compared the structure with PDB ID: 6LU7 (containing the N3 inhibitor) and the best pose obtained from the docking of $\mathrm{M}^{\text {pro }}$ with astragalin.

\subsection{COVID-19 Docking Server Studies}

The docking of astragalin with $\mathrm{M}^{\text {pro }}$ was repeated with the COVID-19 Docking Server [52], a user-friendly platform realized by Kong et al. for docking peptides and antibodies, but also small organic compounds, against some of the main COVID-19-related proteins investigated by implementation of Autodock Vina and CoDockPP [45,52-55]. The ligand file in mol2 format was obtained, starting from informative details on astragalin found in Pubchem (https://pubchem.ncbi.nlm.nih.gov, PubChem CID 5282102) and using the online tool available at the link: http:/ / pasilla.health.unm.edu/tomcat/ biocomp / convert. We selected, in the COVID-19 Docking Server [52], (for ligand preparation, PDB IDs and description of protein targets, scoring and docking procedures see https:/ /ncov.schanglab.org.cn/index.php) as 'Computational Type': 1-molecule Docking and as coronavirus protein target: 'Main protease'. After the docking run, the server provided the pose views for the different binding modes and the corresponding binding energy (score value, $\mathrm{kcal} / \mathrm{mol}$ ) and scoring function (RF-Score, $\mathrm{pKd}$ ) values. The server used as binding center coordinates: $\mathrm{x}=-10.85 ; \mathrm{y}=12.58 ; \mathrm{z}=68.72$ and as target the structure: 6LU7, edited by the developers of the COVID-19 Docking server (the inhibitor N3 [56] was removed). Astragalin-M $\mathrm{M}^{\text {pro }}$ complex was visualized in the structure viewer of the COVID19 Docking Server and UCSF Chimera software [51]. Listed values of score values and RF score values corresponding to the top 10 poses for the complex in Table 2 were obtained as output of the docking experiment performed by the COVID-19 Docking Server (and they were found at https://ncov.schanglab.org.cn/dojmol.php?dir=202012310146538026).

\subsection{LogP, Druglikeness, PAINS, and Toxicity Predictions}

$\log \mathrm{P}$ values (as consensus $\log \mathrm{P}$ ) were predicted by SwissADME software (http: //www.swissadme.ch/ [57]), together with druglikeness and PAINS scores. 
The latter of these were identical to those obtained by us using the PAINS Remover software (http:/ / cbligand.org/PAINS/) to remove pan-assay interference compounds (PAINS) [58] among the phytochemicals under investigation.

To analyze the plant-derived compounds of the present work, we submitted to the PAINS Remover server their structure data as '.sdf' or '.mol' format. Toxicity properties of astragalin were predicted with ADMETlab (http://admet.scbdd.com/calcpre/calc_cf_ single_mol) using the isomeric SMILES format for the compound found in the PubChem database: $\mathrm{C} 1=\mathrm{CC}(=\mathrm{CC}=\mathrm{C} 1 \mathrm{C} 2=\mathrm{C}(\mathrm{C}(=\mathrm{O}) \mathrm{C} 3=\mathrm{C}(\mathrm{C}=\mathrm{C}(\mathrm{C}=\mathrm{C} 3 \mathrm{O} 2) \mathrm{O}) \mathrm{O}) \mathrm{O}[\mathrm{C} @ \mathrm{H}] 4[\mathrm{C} @ @ \mathrm{H}]([\mathrm{C} @ \mathrm{H}]$ $([\mathrm{C} @ \mathrm{H}]([\mathrm{C} @ \mathrm{H}](\mathrm{O} 4) \mathrm{CO}) \mathrm{O}) \mathrm{O}) \mathrm{O}) \mathrm{O}$.

\section{Results and Discussion}

$\mathrm{M}^{\text {pro }}$ (also called $3 \mathrm{CL}^{\text {pro}}$ ) protease is considered an attractive protein target in COVID19 drug discovery and, in particular, for the screening of compounds that could inhibit the replication of coronaviruses [39]. The SARS-CoV-2 protease shares more than $95 \%$ identity with SARS-CoV-1 $\mathrm{M}^{\text {pro }}[59]$ and has a fundamental role in the life cycle of coronaviruses. No similar homologues are present in humans, rendering it a first-choice target in selective anti-COVID-19 therapy, and noteworthily, some of the repurposed drugs [35] used for COVID-19 therapy are protease inhibitors [60]. Based on the prominent role of $\mathrm{M}^{\text {pro }}$ as a SARS-CoV-2 target, 10 phytochemicals (Figure 2) identified in Opuntia ficus-indica were docked to the $\mathrm{M}^{\text {pro }}$ structure with Mcule-1-Click [41,44], a docking server powered by Autodock Vina [45].

Five of the studied phytochemicals (from two phytochemical families: polyphenol acids and flavonoids) were endowed with a high affinity towards $\mathrm{M}^{\mathrm{pro}}$, with binding energy values lower than $-7.0 \mathrm{kcal} / \mathrm{mol}$ associated with the top ranked poses, as reported in Table 1.

In particular, astragalin showed, in silico, the highest affinity score (with a binding energy of $-7.9 \mathrm{kcal} / \mathrm{mol}$ computed for the top scoring pose, Table 1) and, thus, the most stable complex for $\mathrm{M}^{\text {pro }}$. The predicted stability was also higher than that previously reported for the protease N3 inhibitor [61]. Interestingly, astragalin showed higher affinity than both commercial anti-COVID-19 drugs, like chloroquine, and natural molecules supposed to fight against the SARS-CoV-2 infection, like artemisinin and hesperidin, that showed binding energies ranging from -4.1 to $-5.8 \mathrm{kcal} / \mathrm{mol}$ as emerged from previous computational studies on $\mathrm{M}^{\text {pro }}$ inhibitors [62]. Other good binding energy scores were predicted for isorhamnetin, quercetin 5,4'-dimethyl ether, and isorhamnetin 3-O-glucoside, as well as for 3-O-caffeoyl quinic acid $(-7.1 \mathrm{kcal} / \mathrm{mol}$, for the top ranked pose). 


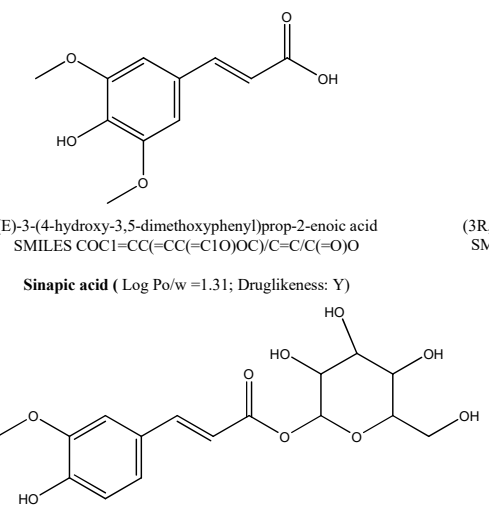

[3,4,5-trihydroxy-6-(hydroxymethyl)oxan-2-yl] 3-(4-hydroxy-3-methoxyphenyl)prop-2 SMILES $\mathrm{COCl}=\mathrm{C}(\mathrm{C}=\mathrm{CC}(=\mathrm{C} 1) \mathrm{C}=\mathrm{CC}(=\mathrm{O}) \mathrm{OC} 2 \mathrm{C}(\mathrm{C}(\mathrm{C}(\mathrm{C}(\mathrm{O} 2) \mathrm{CO}) \mathrm{O}) \mathrm{O}) \mathrm{O}) 0$

Ferulic acid hexoside ( $\log \mathrm{Po} / \mathrm{w}=-0.37$; Druglikeness: $\mathrm{Y}$ )

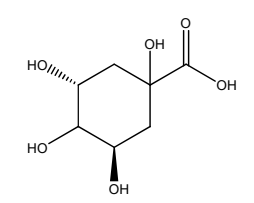

R,5R)-1,3,4,5-tetrahydroxycyclohexane-1-carboxylic aci等] $(\mathrm{C}[\mathrm{C} @ @ \mathrm{H}](\mathrm{CCl}(\mathrm{C}(=)) \mathrm{O}) \mathrm{O}) \mathrm{O}) \mathrm{O}) 0$

Quinic acid ( Log Po/w =-1.69; Druglikeness: Y)<smiles>CCc1cc(C)cc2oc(-c3ccc(OC)c(C)c3)c(O)c(=O)c12</smiles>

3,7-dihydroxy-2-(3-hydroxy-4-methoxyphenyl)-5-methoxychromen-4-one
SMILES $\mathrm{COCl}=\mathrm{C}(\mathrm{C}=\mathrm{C}(\mathrm{C}=\mathrm{Cl}) \mathrm{C} 2=\mathrm{C}(\mathrm{C}=\mathrm{O}) \mathrm{C} 3=\mathrm{C}(\mathrm{O} 2) \mathrm{C}=\mathrm{C}(\mathrm{C}=\mathrm{C}$ (3) $) \mathrm{O}) \mathrm{O}) \mathrm{O}$

Quercetin 5,4'-dimethyl ether ( $\log \mathrm{Po} / \mathrm{w}=2.04$; Druglikeness: $\mathrm{Y})$

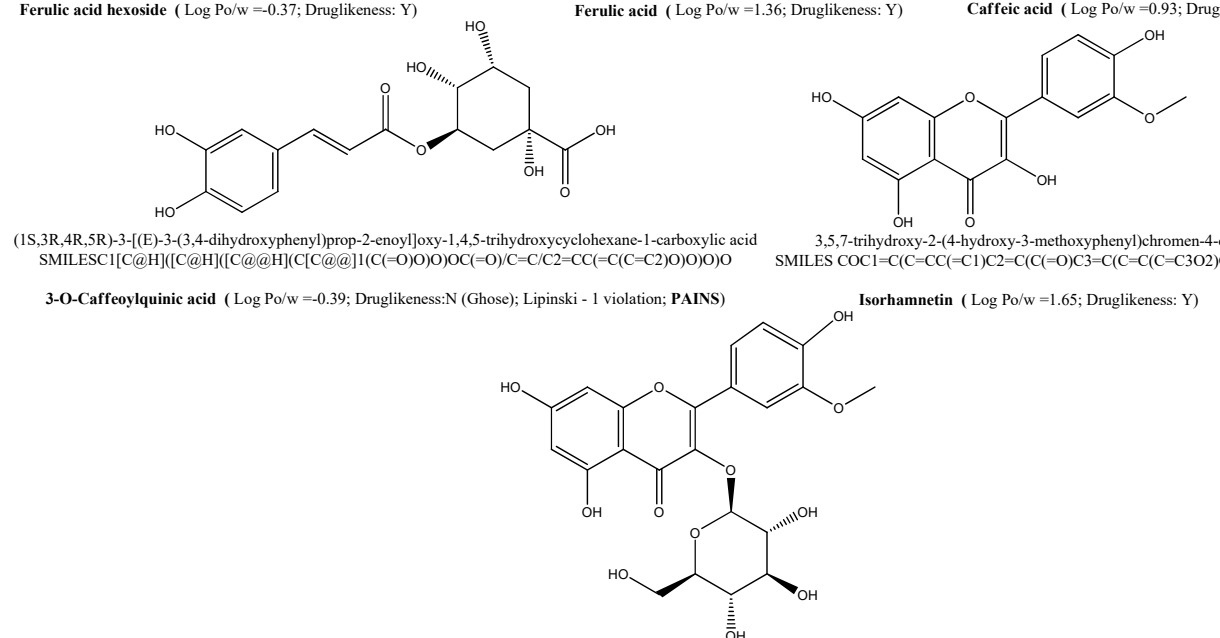<smiles>COc1cc(/C=C/C(=O)O)ccc1O</smiles>

3-(4-hydroxy-3-methoxyphenyl)prop-2-enoic acid (E)-3-(4-hydroxy-3-methoxyphenyl)prop-2-enoic acid
SMILES COCl $=\mathrm{C}(\mathrm{C}=\mathrm{CC}(=\mathrm{Cl}) / \mathrm{C}=\mathrm{C} / \mathrm{C}(=\mathrm{O}) \mathrm{O}) \mathrm{O}$

Ferulic acid $(\log \mathrm{Po} / \mathrm{w}=1.36$; Druglikeness: $\mathrm{Y})$<smiles>O=C(O)/C=C/c1ccc(O)c(O)c1</smiles>

(E)-3-3-3,4-dihydroxyphenyl)prop-2-enoic acid

5,7-dihydroxy-2-(4-hydroxy-3-methoxyphenyl)-3-[(2S,3R,4S,5S,6R)-3,4,5-trihydroxy-6-(hydroxymethyl)oxan-2-yl] oxychromen-4-one

Isorhamnetin-3-O-glucoside ( $\log \mathrm{Po} / \mathrm{w}=0.12$; Druglikeness: $\mathrm{Y}$ (Ghose); Lipinski - 2 violations)<smiles>O=c1c(O[C@@H]2O[C@H](CO)[C@@H](O)[C@H](O)[C@H]2O)c(-c2ccc(Cl)cc2)oc2cc(O)cc(O)c12</smiles>

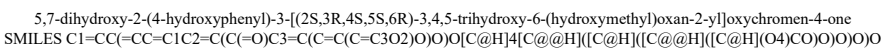

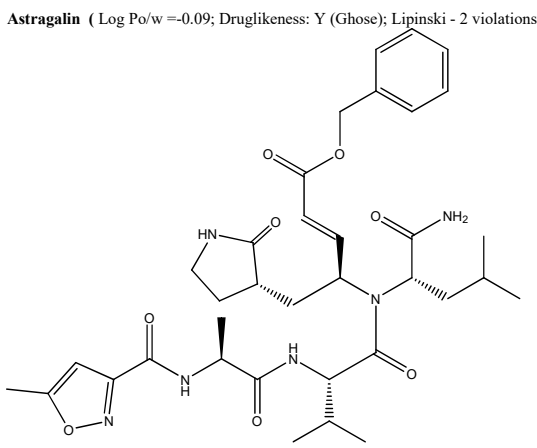

$\mathrm{N}-[(5-\mathrm{Methy}-3-\mathrm{s}$

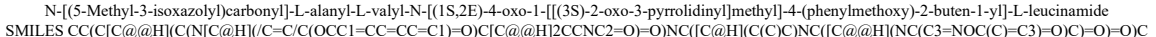

$\mathrm{N} 3$ inhibitor ( Log Po/w =2.69; Druglikeness: N (Ghose); Lipinski - 2 violations; Structural alert: Michael acceptor)

Figure 2. Structure representations for the $M^{\text {pro }}$ ligands investigated in this work with IUPAC and use names, SMILES strings, predicted LogP values, druglikeness, and PAINS scores (where applicable). 
Table 1. Binding affinities of Opuntia-derived compounds to Mpro. Compound structures were found in the PubChem database (https:/ / pubchem.ncbi.nlm.nih.gov/), from which SMILES strings were extracted, or drawn in 2D using the molecular editor of Mcule 1-Click docking platform [44] and docked against the crystal structure of unliganded SARS-CoV-2 main protease (PDB ID: 6Y84). The binding energy (BE) values (scores of top ranked poses and averages of the top four poses \pm standard deviation, in $\mathrm{kcal} / \mathrm{mol}$ ) are listed below.

\begin{tabular}{|c|c|c|c|c|}
\hline Compound Name & $\begin{array}{c}\text { Mpro } \\
\text { BE of Top } \\
\text { Scoring Pose }\end{array}$ & $\begin{array}{c}\text { Mpro } \\
\text { BE-Average } \\
\text { Score }\end{array}$ & $\begin{array}{l}\text { Standard } \\
\text { Deviation }\end{array}$ & $\begin{array}{c}\text { Reference } \\
\text { on Compound } \\
\text { Detection in } \\
\text { Opuntia spp. }\end{array}$ \\
\hline sinapic acid & -6.1 & -5.7 & 0.2 & Elkadi et al. [32] \\
\hline ferulic acid & -5.7 & -5.65 & 0.05 & $\begin{array}{c}\text { Guevara-Figueroa } \\
\text { et al. }[63]\end{array}$ \\
\hline ferulic acid hexoside & -6.8 & -6.625 & 0.178 & Elkadi et al. [32] \\
\hline $\begin{array}{c}\text { 3-O-caffeoyl } \\
\text { quinic acid }\end{array}$ & -7.1 & -6.925 & 0.249 & Elkadi et al. [32] \\
\hline quinic acid & -5.7 & -5.25 & 0.36 & Ammar et al. [64] \\
\hline caffeic acid & -5.7 & -5.625 & 0.083 & Ammar et al. [64] \\
\hline isorhamnetin & -7.3 & -6.625 & 0.536 & Elkadi et al. [32] \\
\hline $\begin{array}{l}\text { isorhamnetin } \\
\text { 3-O-glucoside }\end{array}$ & -7.5 & -6.75 & 0.46 & $\begin{array}{c}\text { Guevara-Figueroa } \\
\text { et al. [63] }\end{array}$ \\
\hline $\begin{array}{c}\text { quercetin } \\
5,4^{\prime} \text {-dimethyl ether }\end{array}$ & -7.3 & -6.375 & 0.683 & Elkadi et al. [32] \\
\hline astragalin & -7.9 & -7.2 & 0.4 & Elkadi et al. [32] \\
\hline N3 inhibitor [61] & -7.6 & & & Bharadwaj et al. [61] \\
\hline
\end{tabular}

We examined the astragalin-protease complex structure for the pose with the lowest binding energy by the ProteinPlus software and noticed that the plant compound was involved in multiple H-bonding, with residues Phe140 and Glu166 of the viral protein, two main amino acid residues also involved in the interaction of N3 inhibitor with the same protease target $[56,65]$. Interestingly, these two residues were also previously associated with the interaction of other molecules investigated as anti-COVID-19 drugs and endowed with $\mathrm{M}^{\text {pro }}$ inhibitory activity $[66,67]$.

Multiple H-bonding was also predicted by ProteinPlus in the cases of 3-O-caffeoyl quinic acid and SARS-CoV-2 M ${ }^{\text {pro }}$ Cys145, Ser144, His163, Leu141, and Thr26 (Figure 4A), as well of isorhamnetin with protease Gln189, Thr26, and Asn142 residues (Figure 4B).

Isorhamnetin 3-O-glucoside and quercetin 5,4'-dimethyl ether were predicted to bind $\mathrm{M}^{\text {pro }}$ not only by means of the molecule H-bonding with Thr26, Thr24, Gln189, Leu141, Gly143, Asn142 (isorhamnetin 3-O-glucoside), His41, and Asn142 (quercetin 5,4'-dimethyl ether), but also due to the hydrophobic contacts with Thr25 and His41, respectively (Figure 4C,D).

In our prediction, isorhamnetin formed $\mathrm{H}$-bonds with three protease residues, while its glucoside form interacted with six amino acids involving three additional $\mathrm{H}$-bonds, as we expected for its more highly hydroxylated nature, and the hydrophobic interaction with Thr25 (Figure 4C,D).

Comparing isorhamnetin and quercetin 5,4'-dimethyl ether, the latter was involved in a hydrophobic interaction with protease His41, while the former, with an additional phenolic $\mathrm{OH}$, showed a higher propensity for H-bonding (Figure 4B,D). Nevertheless, the overall binding energies (BE for the top-ranked poses and $\mathrm{BE}$-average scores) that emerged from our simulation for the complexes formed by these two compounds with $\mathrm{M}^{\text {pro }}$ were quite similar, as shown in Table 1. 


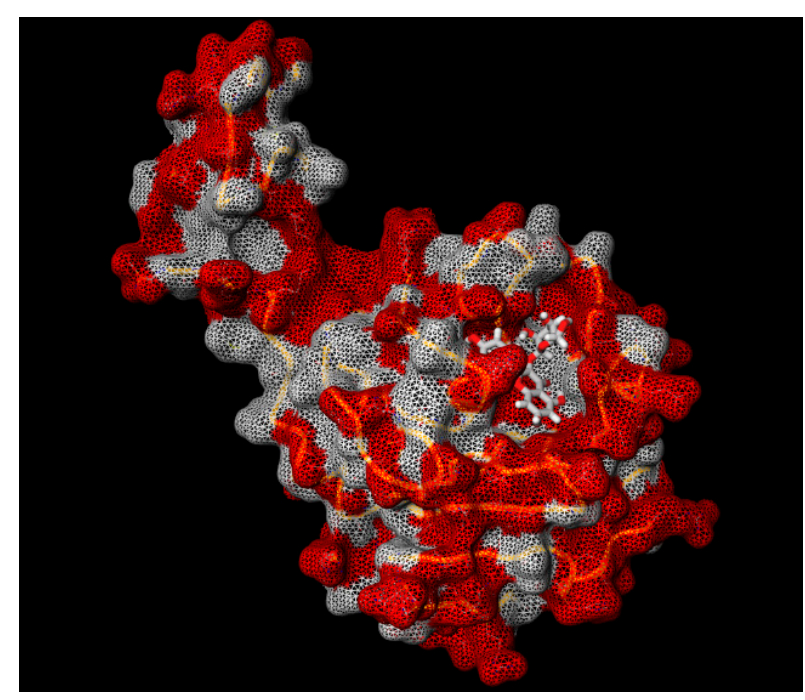

(A)

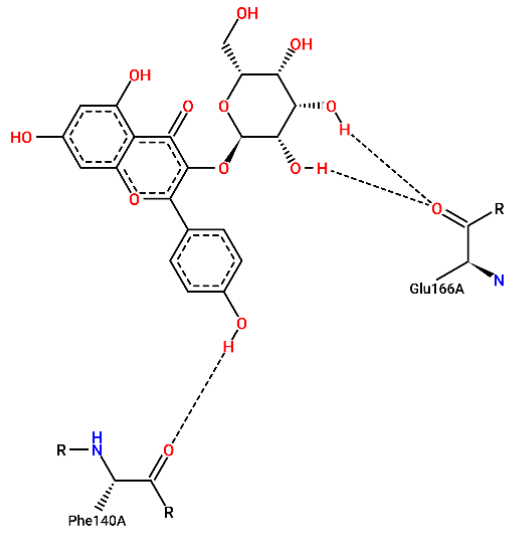

(C)

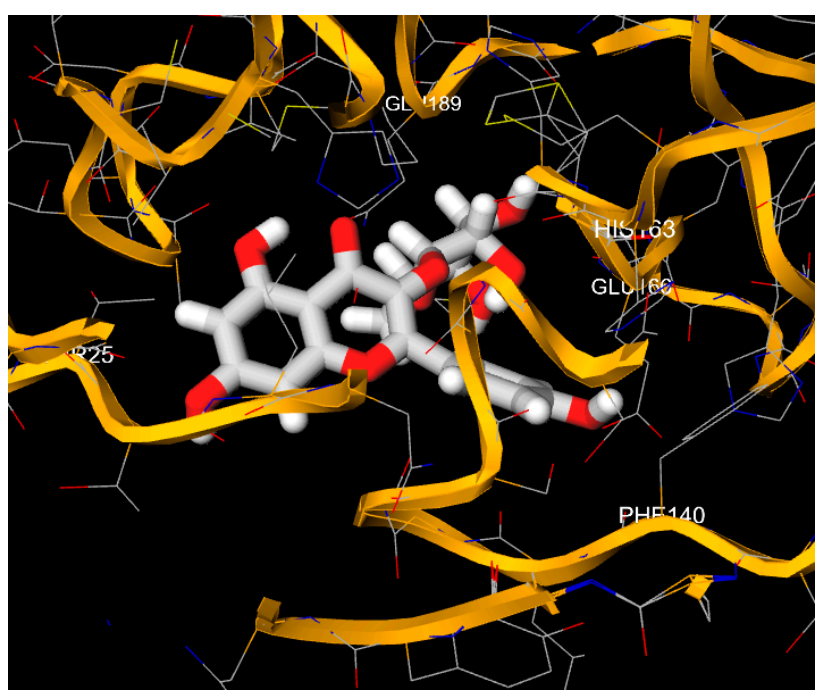

(B)
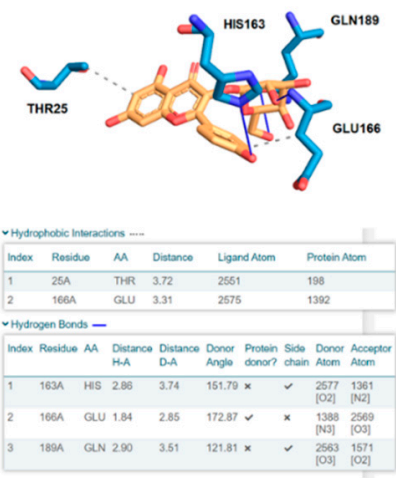

(D)

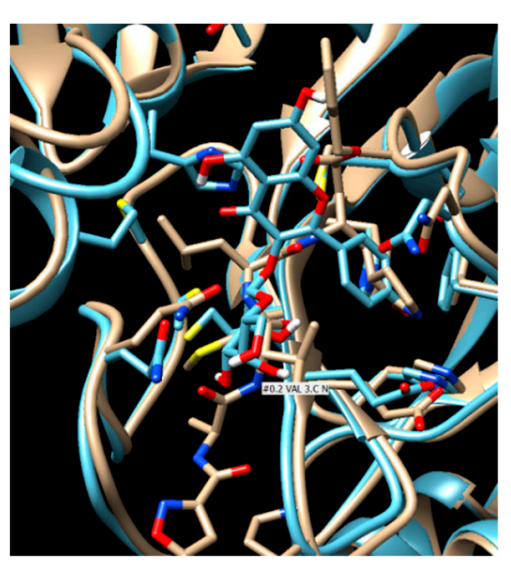

(E)

Figure 3. Top ranked pose views (A,B), 2D protein-ligand interaction diagrams obtained by ProteinPlus (C) and PLIP (Protein-Ligand Interaction Profiler, D) for the interaction between astragalin and $\mathrm{M}^{\text {pro }}$ and the N3 inhibitor/astragalin(cyan)-bound Mpro structural comparison (E), obtained by the matchmaker tool embedded in UCSF Chimera [51]. 


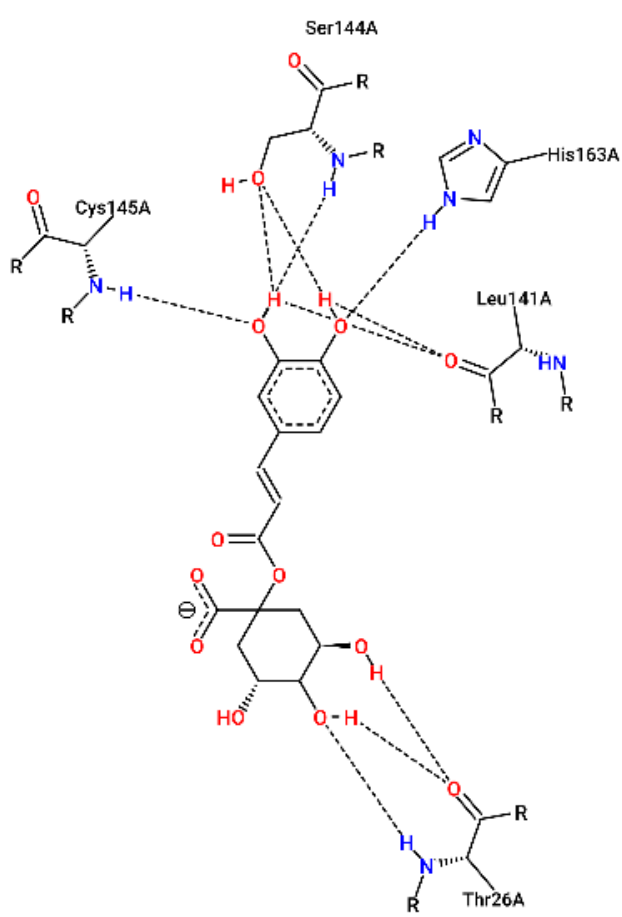

(A)

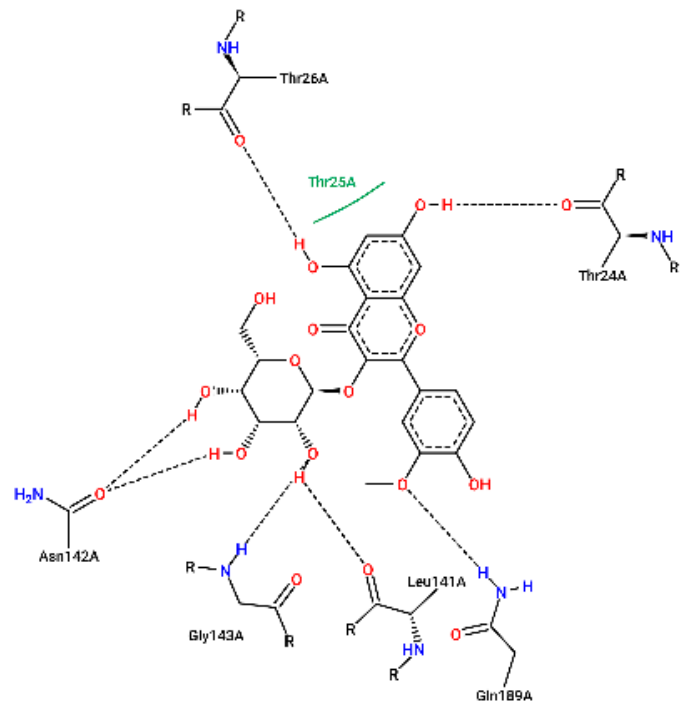

(C)

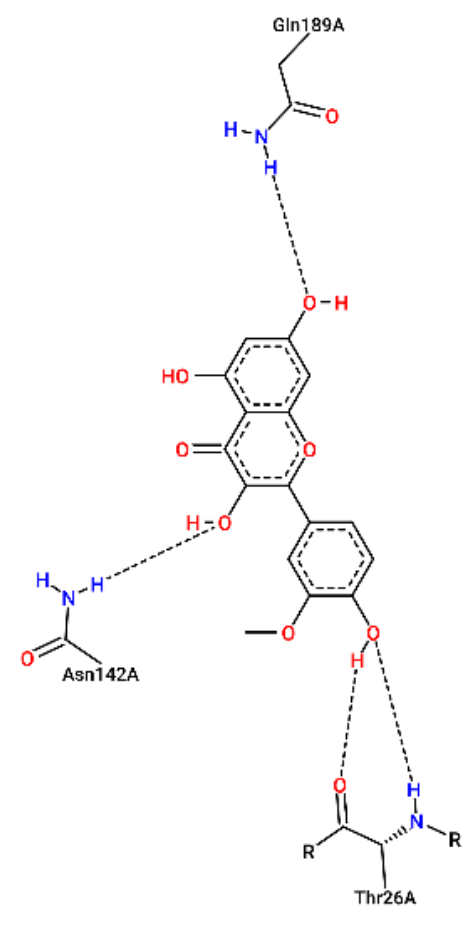

(B)

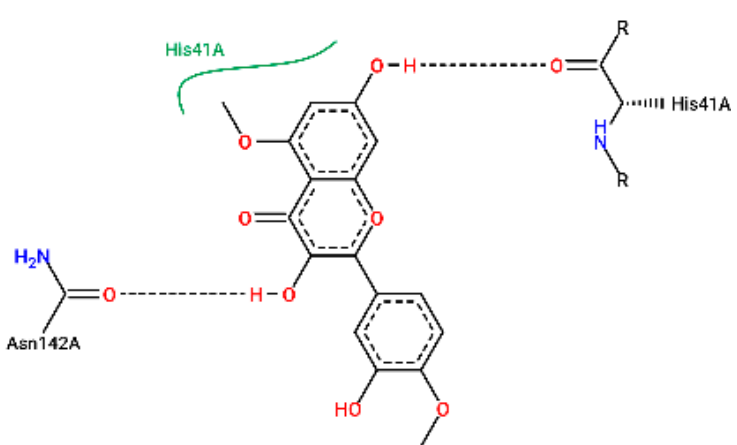

Figure 4. 2D protein-ligand interaction diagrams obtained by ProteinPlus at the active site of $\mathrm{M}^{\text {pro }}$ for 3-O-caffeoyl quinic acid (A), isorhamnetin (B), isorhamnetin 3-O-glucoside (C), and quercetin 5,4'-dimethyl ether (D). 
Overall, despite more H-bonding interaction being observed for 3-O-caffeoyl quinic acid, isorhamnetin, and isorhamnetin 3-O-glucoside, astragalin was predicted by ProteinPlus to interact with Phe140 and Glu166, which are two main acceptors that have already been described in the literature for the interaction of sugar-containing ligands with the same target [68] and for the N3 inhibitor of $\mathrm{M}^{\text {pro }}$ [56].

However, the higher affinity for $\mathrm{M}^{\text {pro }}$ predicted for astragalin with respect to the other natural ligands could not be fully explained by the only two H-bonds evidenced by ProteinPlus, and thus, we decided to investigate this aspect in more detail, using the program PLIP (Protein-Ligand Interaction Profiler, https: / / plip-tool.biotec.tu-dresden.de/), for better describing the interactions occurring between the protease binding site amino acids and the ligand.

Additional H-bondings with His163 and Gln189, as well as hydrophobic interactions with Thr25 and Glu166, were revealed for astragalin in a complex with Mpro by PLIP (Figure 3D). We superimposed and aligned the protein complex structures containing the N3 inhibitor (PDB ID: 6LU7) and astragalin (using the best ranked pose for the docking of the protease with the natural compound). By complex structures comparison, we observed that the sugar moiety of astragalin, whose H-bonding with Gln189 was evidenced by PLIP software, was found in the spatial region where the two Val3-involving amide bonds of N3 inhibitor were placed (Figure 3E), whilst the aromatic flavonol moieties lay in the region occupied by the hydrophobic/aromatic 2-oxo-3-pyrrolidinyl and benzyl moieties of the N3 inhibitor (Figure 3E), where they formed hydrophobic interactions with Thr25 and Glu166, as well as H-bonding with His163 (Figure 3D).

The docking experiment with astragalin was repeated using COVID-19 Docking Server [52], a web platform for docking different classes of ligands to SARS-CoV-2-associated protein targets. The dockings on this web-based server were performed by us choosing the exhaustiveness level as 12, with a higher level of this parameter being considered to provide more precise docking results [52]. This web-based docking platform has been carefully validated by the developers to evaluate their docking protocols, by conducting several re-dock experiments for those targets whose experimental complex structures were available. Most of the complex structures, including that of the $\mathrm{M}^{\text {pro }}$ with $\mathrm{N} 3$ inhibitor, were reproduced by using the docking procedure on the web server (Tables S1 and S2 in Supplementary Information of [52]).

The main results of this investigation are reported in Table 2. Interestingly, astragalin showed a high affinity for the selected COVID-19 protein target, with binding energy scores ranging from -6.90 to $-8.70 \mathrm{kcal} / \mathrm{mol}$ and $\mathrm{RF}(\mathrm{pKd}$ ) scores varying between 5.40 and 6.03 .

Table 2. COVID-19 Docking Server [52] analysis of astragalin-Mpro binding. Pose numbers, scoring function (RF-Score, $\mathrm{pKd}$ ), and binding energy (score value, $\mathrm{kcal} / \mathrm{mol}$ ) values are reported.

\begin{tabular}{ccc}
\hline Pose $\mathbf{n .}$ & $\begin{array}{c}\text { RF-Score } \\
\text { (pKd) }\end{array}$ & $\begin{array}{c}\text { Score Value } \\
\text { (Kcal/mol) }\end{array}$ \\
\hline 1 & 6.03 & -8.70 \\
\hline 2 & 5.95 & -8.40 \\
3 & 5.51 & -7.60 \\
4 & 5.40 & -7.40 \\
5 & 5.93 & -7.40 \\
6 & 5.68 & -7.30 \\
7 & 5.57 & -7.00 \\
8 & 5.52 & -6.90 \\
9 & 5.34 & -6.90 \\
10 & 5.48 & -6.80 \\
\hline
\end{tabular}

The binding affinity predicted for the top ranked pose of the compound-Mpro complex $(-8.7 \mathrm{kcal} / \mathrm{mol})$ was higher than that $(-7.9 \mathrm{kcal} / \mathrm{mol})$ indicated by $1-C l i c k$ Mcule (Table 1) [44], whilst the structure of the complex (Figure $5 \mathrm{~A}, \mathrm{~B}$ ) resembled only partially that shown in 1-Click Mcule structure viewer. In the complex structure predicted by COVID-19 Docking Server the sugar moiety replaced the astragalin phenol in the proximity of the region of the $\beta$-sheet made of His163-Glu166, belonging to the catalytic pocket (Figure $5 \mathrm{~A}, \mathrm{~B}$ ). 

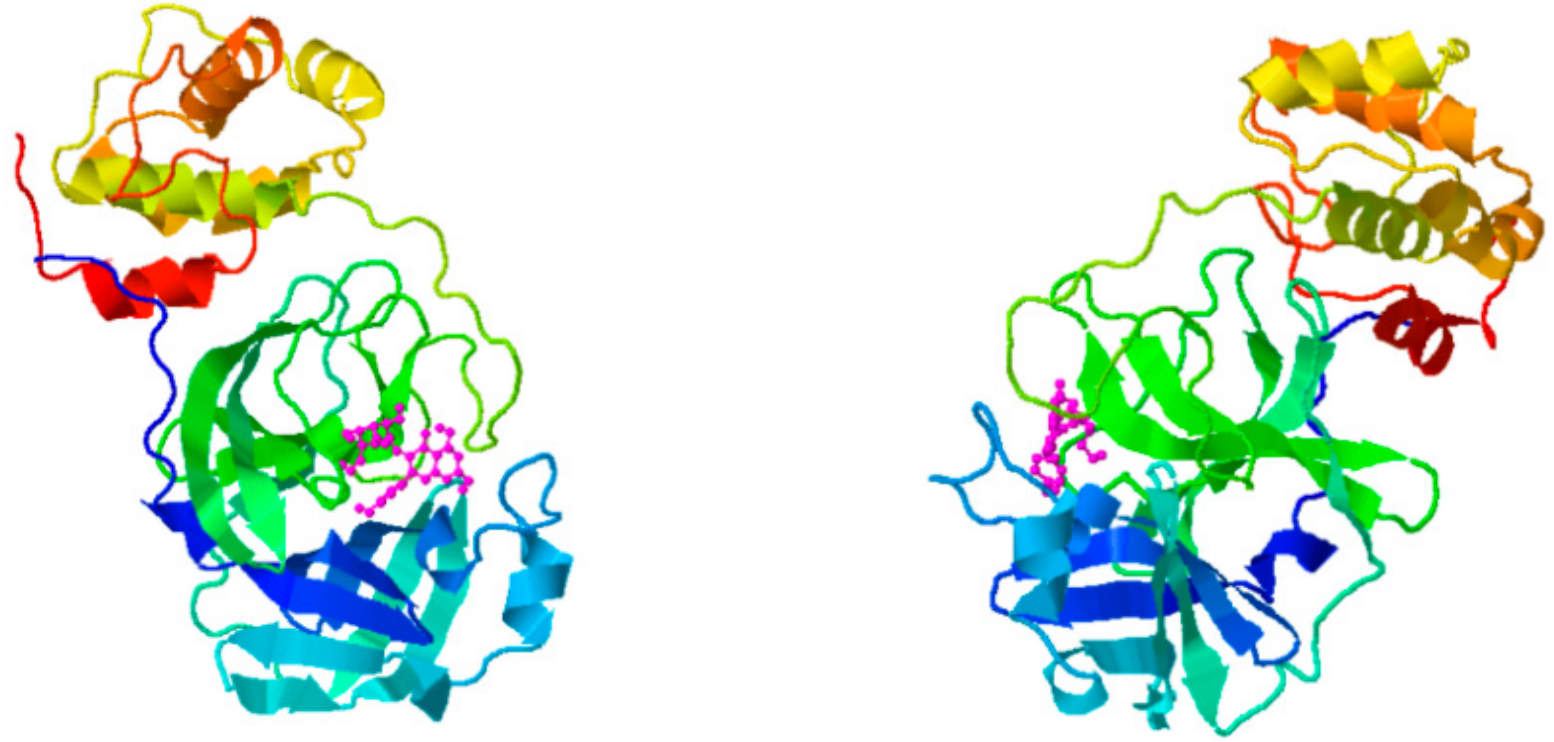

(A)

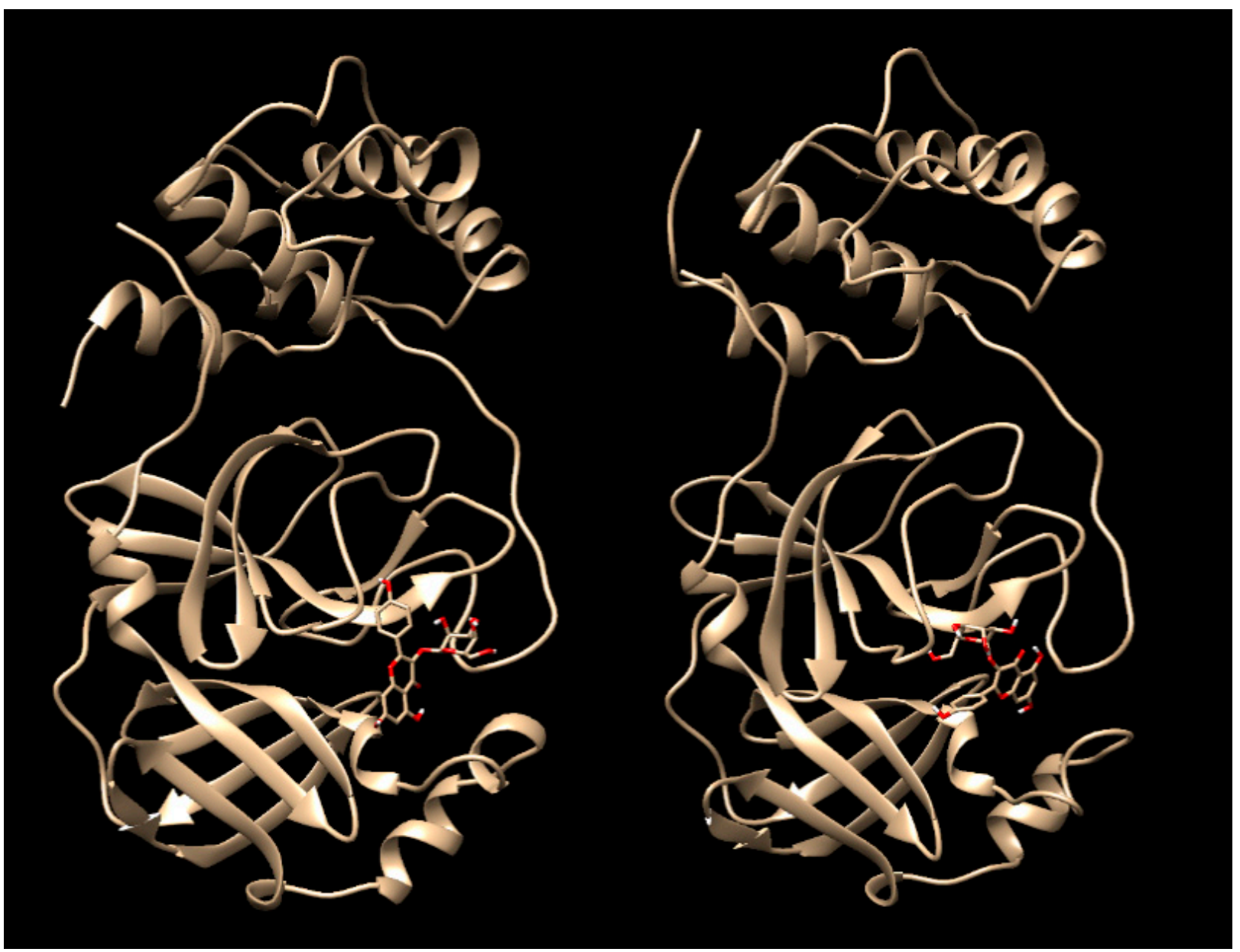

(B)

Figure 5. Top ranked pose views (A) for the interaction between astragalin and $\mathrm{M}^{\text {pro }}$, as predicted by the COVID-19 Docking Server [52]. Comparison of the complex structures predicted for astragalin by 1-Click (B, left) [44] and the COVID-19 Docking Server (B, right) [52], as visualized with UCSF Chimera [51]. 
We identified pan-assay interference compounds (PAINS) in our collection of Opuntiaderived compounds to exclude the molecules with promiscuous behavior that, due to their chemical structures, could lead to false positive results in different biological screening assays. [69] To this scope, we used the PAINS Remover, a software able to identify PAINS in screening libraries. [58]

Out of the 10 evaluated compounds, only 3-O-caffeoyl quinic acid and caffeic acid were filtered out by the PAINS Remover and by SwissADME [57] (Figure 2), indicating no potential PAINS in the majority of the investigated Opuntia phytochemicals, including astragalin, the leading compound that emerged from our study (Figure 2).

The last aspect examined in the present computational study was the potential hepatotoxicity of the most promising Opuntia-derived compound emerging from our work, together with other toxicity properties.

As can be seen in Table 3, there was no significant hepatotoxic effect predicted for astragalin.

This is in accord with what has been reported previously on this flavonol glycoside, including the astragalin hepatoprotective effect [70], and suggests that this compound could be well-tolerated by the liver in a hypothetic therapeutic approach. Moreover, no drug-induced mutagenicity nor any important skin sensitization was predicted (Table 3).

Table 3. Toxicity properties of astragalin predicted by ADMETlab. Notice the low toxic potential of the Opuntia-derived compound under investigation.

\begin{tabular}{cccc}
\hline & $\begin{array}{c}\text { Human Hepatotoxicity } \\
\text { (H-HT) }\end{array}$ & $\begin{array}{c}\text { Skin } \\
\text { Sensitization }\end{array}$ & $\begin{array}{c}\text { Ames Mutagenicity } \\
\text { (Ames) }\end{array}$ \\
\hline $\begin{array}{c}\text { Category * } \\
\text { Probability }\end{array}$ & 0 & 0 & 0 \\
\hline "Category 0: H-HT negative (-); not-sensitizer; Ames negative (-). Category 1: H-HT positive (+); sensitizer; \\
Ames positive (+).
\end{tabular}

The findings of this study are interesting, opening the way to further in silico and in vitro investigations on astragalin and, more generally, on the flavonol glycosides with similar structures extracted from Opuntia spp. for anti-COVID-19 therapeutic approaches.

\section{Conclusions}

We examined 10 compounds discovered in Opuntia ficus-indica, a typical cactus plant of common dietary and phytotherapeutic use, and found that five of them showed a good predicted affinity for the main protease of SARS-CoV-2, a first choice target in the COVID19 drug discovery. Among these phytochemicals, the chiral astragalin emerged as the most promising potential inhibitor of $\mathrm{M}^{\text {pro }}$. This compound showed binding energy scores of $-7.9 \mathrm{kcal} / \mathrm{mol}$ and $-8.7 \mathrm{kcal} / \mathrm{mol}$ (corresponding to the top scoring poses obtained by 1-Click Mcule [44] and the COVID-19 Docking Server [52], respectively), higher than the $\mathrm{M}^{\text {pro }} \mathrm{N} 3$ inhibitor, revealing a strong interaction with the protease target. Overall, this chiral compound interacted with M ${ }^{\text {pro }}$ amino acids like Phe140, His163, Glu166, and Gln189 by H-bonding and with Thr25 and Glu166 by hydrophobic interactions. Interestingly, these are also residues involved in the $\mathrm{M}^{\text {pro }}$ binding of the N3 inhibitor [56]. Moreover, our computational studies suggested that Opuntia-derived flavonol glycosides are interesting derivatives with low toxic potential. These natural products show good binding affinities for $\mathrm{M}^{\mathrm{pro}}$, and their direct use or chemical derivatization could lead to potentially effective treatments for COVID-19. Despite a predicted affinity for $\mathrm{M}^{\text {pro }}$ lower than astragalin, quercetin 5,4'-dimethyl ether, a phytochemical isolated not only from Opuntia ficus-indica, but also from other plants like Rhododendron ellipticum [71], used as folk medicine to suppress cough [72], was an interesting candidate as an $\mathrm{M}^{\text {pro }}$ inhibitor that was still endowed with a good binding affinity $(-7.3 \mathrm{kcal} / \mathrm{mol}$ predicted for the top scoring pose). Since Autodock Vina software tends to underestimate the binding affinity of the ligands for the target [73], our complex could be endowed with an even lower binding energy and, thus, a higher affinity than that computed. In other terms, our study could inspire future 
clinical trials using some of the several commercially available Opuntia ficus-indica dietary supplements to ameliorate health conditions of COVID-19 patients, and from a molecular perspective, it could serve as a starting point for experimental investigations directed towards characterizing the above ligand-protease interactions and the in vitro/in vivo anti-SARS-CoV-2 effects of the different compounds extracted from Opuntia ficus-indica and from other Cactaceae family members.

Author Contributions: All authors contributed equally to the literature collection, writing, experimental design and research, data analysis, editing, and reviewing of the article. All authors have read and agreed to the published version of the manuscript.

Funding: This research did not receive any specific grants from funding agencies in the public, commercial, or not-for-profit sectors.

Institutional Review Board Statement: Not applicable.

Informed Consent Statement: Not applicable.

Acknowledgments: Some of the molecular graphics shown in this work were realized with UCSF Chimera, developed by the Resource for Biocomputing, Visualization, and Informatics at the University of California, San Francisco, with support from NIH P41-GM103311. We are grateful to Gergely Prikler and Gergely Takács (https:/ / mcule.com, Mcule team, Hungary) for their kind support in molecular docking studies. In silico studies were performed by the authors in a smart-working mode (activated by Consiglio Nazionale delle Ricerche-CNR and University of Naples Federico II-UNINA during the COVID-19 crisis). We dedicate this study to all the health care workers and to all the people who suffered and still suffer around the world as a result of the COVID-19 pandemic.

Conflicts of Interest: The authors declare that they have no known competing financial interests or personal relationships that could have appeared to influence the work reported in this paper.

\section{References}

1. Makhdoom, R.; El-Sherif, G.; Hijazi, M.A. Effect of Enzymatic Treatment on Polyphenolics Content in Prickly Pear (Opuntia ficus indica) Juice. Life Sci. J. 2016, 13, 88-93.

2. Erre, P.; Chessa, I.; Nieddu, G.; Jones, P.G. Diversity and spatial distribution of Opuntia spp. in the Mediterranean Basin. J. Arid Environ. 2009, 73, 1058-1066. [CrossRef]

3. Kim, J.-H.; Park, S.-M.; Ha, H.-J.; Moon, C.-J.; Shin, T.-K.; Kim, J.-M.; Lee, N.-H.; Kim, H.-C.; Jang, K.-J.; Wie, M.-B. Opuntia ficus-indica attenuates neuronal injury in in vitro and in vivo models of cerebral ischemia. J. Ethnopharmacol. 2006, 104, 257-262. [CrossRef]

4. El-Mostafa, K.; El Kharrassi, Y.; Badreddine, A.; Andreoletti, P.; Vamecq, J.; El Kebbaj, M.; Latruffe, N.; Lizard, G.; Nasser, B.; Cherkaoui-Malki, M. Nopal cactus (Opuntia ficus-indica) as a source of bioactive compounds for nutrition, health and disease. Molecules 2014, 19, 14879-14901. [CrossRef]

5. Aragona, M.; Lauriano, E.; Pergolizzi, S.; Faggio, C. Opuntia ficus-indica (L.) Miller as a source of bioactivity compounds for health and nutrition. Nat. Prod. Res. 2018, 32, 2037-2049. [CrossRef]

6. Hernández-Urbiola, M.I.; Pérez-Torrero, E.; Rodríguez-García, M.E. Chemical analysis of nutritional content of prickly pads (Opuntia ficus indica) at varied ages in an organic harvest. Int. J. Environ. Res. Public Health 2011, 8, 1287-1295. [CrossRef] [PubMed]

7. Inglese, P.; Barbera, G.; La Mantia, T. Research strategies for the improvement of cactuspear (Opuntia ficus-indica) fruit quality and production. J. Arid Environ. 1995, 29, 455-468. [CrossRef]

8. Snyman, H.A. Growth rate and water-use efficiency of cactus pears Opuntia ficus-indica and O. robusta. Arid Land Res. Manag. 2013, 27, 337-348. [CrossRef]

9. Comparettia, A.; Feboa, P.; Grecoa, C.; Mammanob, M.M.; Orlandoa, S. Potential production of biogas from prinkly pear (Opuntia ficus-indica L.) in Sicilian uncultivated areas. Chem. Eng. 2017, 58. [CrossRef]

10. do Nascimento Santos, T.; Dutra, E.D.; do Prado, A.G.; Leite, F.C.B.; de Souza, R.d.F.R.; dos Santos, D.C.; de Abreu, C.A.M.; Simões, D.A.; de Morais, M.A., Jr.; Menezes, R.S.C. Potential for biofuels from the biomass of prickly pear cladodes: Challenges for bioethanol and biogas production in dry areas. Biomass Bioenergy 2016, 85, 215-222. [CrossRef]

11. Neffar, S.; Chenchouni, H.; Beddiar, A.; Redjel, N. Rehabilitation of degraded rangeland in drylands by prickly pear (Opuntia ficus-indica L.) plantations: Effect on soil and spontaneous vegetation. Ecol. Balk. 2013, 5, 63-76.

12. Nefzaoui, A.; Louhaichi, M.; Ben Salem, H. Cactus as a tool to mitigate drought and to combat desertification. J. Arid Land Stud. 2014, 24, 121-124.

13. Bautista-Cruz, A.; Leyva-Pablo, T.; de León-González, F.; Zornoza, R.; Martínez-Gallegos, V.; Fuentes-Ponce, M.; RodríguezSánchez, L. Cultivation of Opuntia ficus-indica under different soil management practices: A possible sustainable agricultural 
system to promote soil carbon sequestration and increase soil microbial biomass and activity. Land Degrad. Dev. 2018, $29,38-46$. [CrossRef]

14. Ayadi, M.; Abdelmaksoud, W.; Ennouri, M.; Attia, H. Cladodes from Opuntia ficus indica as a source of dietary fiber: Effect on dough characteristics and cake making. Ind. Crop. Prod. 2009, 30, 40-47. [CrossRef]

15. Barbera, G.; Carimi, F.; Inglese, P. Past and present role of the Indian-fig prickly-pear (Opuntia ficus-indica (L.) Miller, Cactaceae) in the agriculture of Sicily. Econ. Bot. 1992, 46, 10-20. [CrossRef]

16. Barba, F.J.; Garcia, C.; Fessard, A.; Munekata, P.E.; Lorenzo, J.M.; Aboudia, A.; Ouadia, A.; Remize, F. Opuntia Ficus Indica Edible Parts: A Food and Nutritional Security Perspective. Food Rev. Int. 2020, 1-23. [CrossRef]

17. Costa, R.G.; Beltrão Filho, E.M.; de Medeiros, A.N.; Givisiez, P.E.N.; do Egypto, R.d.C.R.; Melo, A.A.S. Effects of increasing levels of cactus pear (Opuntia ficus-indica L. Miller) in the diet of dairy goats and its contribution as a source of water. Small Rumin. Res. 2009, 82, 62-65. [CrossRef]

18. Gebretsadik, G.; Animut, G.; Tegegne, F. Assessment of the potential of cactus pear (Opuntia ficus indica) as livestock feed in Northern Ethiopia. Livest. Res. Rural Dev. 2013, 25, 1-10.

19. Kaur, M.; Kaur, A.; Sharma, R. Pharmacological actions of Opuntia ficus indica: A Review. J. Appl. Pharm. Sci. 2012, 2, 15-18. [CrossRef]

20. Andreu, L.; Nuncio-Jáuregui, N.; Carbonell-Barrachina, Á.A.; Legua, P.; Hernández, F. Antioxidant properties and chemical characterization of Spanish Opuntia ficus-Indica Mill. cladodes and fruits. J. Sci. Food Agric. 2018, 98, 1566-1573. [CrossRef]

21. Butera, D.; Tesoriere, L.; Di Gaudio, F.; Bongiorno, A.; Allegra, M.; Pintaudi, A.M.; Kohen, R.; Livrea, M.A. Antioxidant activities of Sicilian prickly pear (Opuntia ficus indica) fruit extracts and reducing properties of its betalains: Betanin and indicaxanthin. $J$. Agric. Food Chem. 2002, 50, 6895-6901. [CrossRef]

22. Benayad, Z.; Martinez-Villaluenga, C.; Frias, J.; Gomez-Cordoves, C.; Es-Safi, N.E. Phenolic composition, antioxidant and anti-inflammatory activities of extracts from Moroccan Opuntia ficus-indica flowers obtained by different extraction methods. Ind. Crop. Prod. 2014, 62, 412-420. [CrossRef]

23. Antunes-Ricardo, M.; Gutiérrez-Uribe, J.A.; Martínez-Vitela, C.; Serna-Saldívar, S.O. Topical anti-inflammatory effects of isorhamnetin glycosides isolated from Opuntia ficus-indica. BioMed Res. Int. 2015, 2015, 847320. [CrossRef]

24. Ammar, I.; Salem, M.B.; Harrabi, B.; Mzid, M.; Bardaa, S.; Sahnoun, Z.; Attia, H.; Ennouri, M. Anti-inflammatory activity and phenolic composition of prickly pear (Opuntia ficus-indica) flowers. Ind. Crop. Prod. 2018, 112, 313-319. [CrossRef]

25. Frati, A.C.; Jiménez, E.; Ariza, C.R. Hypoglycemic effect of Opuntia ficus indica in non insulin-Dependent diabetes mellitus patients. Phytother. Res. 1990, 4, 195-197. [CrossRef]

26. Leem, K.-H.; Kim, M.-G.; Hahm, Y.-T.; Kim, H.K. Hypoglycemic effect of Opuntia ficus-indica var. saboten is due to enhanced peripheral glucose uptake through activation of AMPK/p38 MAPK pathway. Nutrients 2016, 8, 800. [CrossRef]

27. Elshehy, H.; Salah, S.; Abdel-Mawla, E.; Agamy, N. Protective Effect of Opuntia ficus-indica against Diabetes in Alloxan-induced Diabetic Rats. Can. J. Clin. Nutr. 2020, 8, 20-34. [CrossRef]

28. Yao, X.; Hu, H.; Qin, Y.; Liu, J. Development of antioxidant, antimicrobial and ammonia-sensitive films based on quaternary ammonium chitosan, polyvinyl alcohol and betalains-rich cactus pears (Opuntia ficus-indica) extract. Food Hydrocoll. 2020, 106, 105896. [CrossRef]

29. El-Hawary, S.S.; Sobeh, M.; Badr, W.K.; Abdelfattah, M.A.; Ali, Z.Y;; El-Tantawy, M.E.; Rabeh, M.A.; Wink, M. HPLC-PDAMS/MS profiling of secondary metabolites from Opuntia ficus-indica cladode, peel and fruit pulp extracts and their antioxidant, neuroprotective effect in rats with aluminum chloride induced neurotoxicity. Saudi J. Biol. Sci. 2020, 27, 2829-2838. [CrossRef]

30. Rasoulpour, R.; Izadpanah, K.; Afsharifar, A. Opuntin B, the antiviral protein isolated from prickly pear (Opuntia ficus-indica (L.) Miller) cladode exhibits ribonuclease activity. Microb. Pathog. 2020, 140, 103929. [CrossRef] [PubMed]

31. Chauhan, S.; Sheth, N.; Jivani, N.; Rathod, I.; Shah, P. Biological actions of Opuntia species. Syst. Rev. Pharm. 2010, 1, 146. [CrossRef]

32. Elkady, W.M.; Bishr, M.M.; Abdel-Aziz, M.M.; Salama, O.M. Identification and isolation of anti-pneumonia bioactive compounds from Opuntia ficus-indica fruit waste peels. Food Funct. 2020, 11, 5275-5283. [CrossRef]

33. Roviello, V.; Roviello, G.N. Lower COVID-19 mortality in Italian forested areas suggests immunoprotection by Mediterranean plants. Environ. Chem. Lett. 2020. [CrossRef] [PubMed]

34. Costanzo, M.; De Giglio, M.A.R.; Roviello, G.N. Anti-Coronavirus Vaccines: Past Investigations on SARS-CoV-1 and MERS$\mathrm{CoV}$, the Approved Vaccines from BioNTech/Pfizer, Moderna, Oxford/AstraZeneca and others under Development Against SARS-CoV-2 Infection. Curr. Med. Chem. 2021, 28. [CrossRef]

35. Costanzo, M.; De Giglio, M.A.R.; Roviello, G.N. SARS CoV-2: Recent Reports on Antiviral Therapies Based on Lopinavir/Ritonavir, Darunavir/Umifenovir, Hydroxychloroquine, Remdesivir, Favipiravir and Other Drugs for the Treatment of the New Coronavirus. Curr. Med. Chem. 2020, 27. [CrossRef] [PubMed]

36. Borbone, N.; Piccialli, G.; Roviello, G.N.; Oliviero, G. Nucleoside Analogs and Nucleoside Precursors as Drugs in the Fight against SARS-CoV-2 and Other Coronaviruses. Molecules 2021, 26, 986. [CrossRef]

37. Yang, Y.; Islam, M.S.; Wang, J.; Li, Y.; Chen, X. Traditional Chinese medicine in the treatment of patients infected with 2019-new coronavirus (SARS-CoV-2): A review and perspective. Int. J. Biol. Sci. 2020, 16, 1708. [CrossRef]

38. Vicidomini, C.; Roviello, V.; Roviello, G.N. Molecular Basis of the Therapeutical Potential of Clove (Syzygium aromaticum L.) and Clues to Its Anti-COVID-19 Utility. Molecules 2021, 26, 1880. [CrossRef] 
39. Bacha, U.; Barrila, J.; Velazquez-Campoy, A.; Leavitt, S.A.; Freire, E. Identification of novel inhibitors of the SARS coronavirus main protease 3CLpro. Biochemistry 2004, 43, 4906-4912. [CrossRef]

40. Berman, H.M.; Battistuz, T.; Bhat, T.N.; Bluhm, W.F.; Bourne, P.E.; Burkhardt, K.; Feng, Z.; Gilliland, G.L.; Iype, L.; Jain, S.; et al. The Protein Data Bank. Acta Crystallogr. Sect. D Biol. Crystallogr. 2002, 58, 899-907. [CrossRef]

41. Potemkin, V.; Potemkin, A.; Grishina, M. Internet Resources for Drug Discovery and Design. Curr. Top. Med. Chem. 2019, 18, 1955-1975. [CrossRef] [PubMed]

42. Fik-Jaskółka, M.A.; Mkrtchyan, A.F.; Saghyan, A.S.; Palumbo, R.; Belter, A.; Hayriyan, L.A.; Simonyan, H.; Roviello, V.; Roviello, G.N. Spectroscopic and SEM evidences for G4-DNA binding by a synthetic alkyne-containing amino acid with anticancer activity. Spectrochim. Acta Part A Mol. Biomol. Spectrosc. 2020, 229, 117884. [CrossRef]

43. Fik-Jaskółka, M.A.; Mkrtchyan, A.F.; Saghyan, A.S.; Palumbo, R.; Belter, A.; Hayriyan, L.A.; Simonyan, H.; Roviello, V.; Roviello, G.N. Biological macromolecule binding and anticancer activity of synthetic alkyne-containing l-phenylalanine derivatives. Amino Acids 2020, 52, 755-769. [CrossRef]

44. Kiss, R.; Sandor, M.; Szalai, F.A. http:/ /Mcule.com: A public web service for drug discovery. J. Cheminform. 2012, 4. [CrossRef]

45. Trott, O.; Olson, A.J. AutoDock Vina: Improving the speed and accuracy of docking with a new scoring function, efficient optimization, and multithreading. J. Comput. Chem. 2009. [CrossRef]

46. Umesh, K.D.; Selvaraj, C.; Singh, S.K.; Dubey, V.K. Identification of new anti-nCoV drug chemical compounds from Indian spices exploiting SARS-CoV-2 main protease as target. J. Biomol. Struct. Dyn. 2020, 1-9. [CrossRef]

47. Roviello, V.; Musumeci, D.; Mokhir, A.; Roviello, G.N. Evidence of protein binding by a nucleopeptide based on a thyminedecorated L-diaminopropanoic acid through CD and in silico studies. Curr. Med. Chem. 2021, 28. [CrossRef]

48. Chakraborti, S.; Bheemireddy, S.; Srinivasan, N. Repurposing drugs against main protease of SARS-CoV-2: Mechanism-based insights supported by available laboratory and clinical data. Mol. Omics 2020. [CrossRef]

49. Rarey, M.; Steinegger, R.; Nittinger, E.; Meyder, A.; Flachsenberg, F.; Fährrolfes, R.; Diedrich, K.; Schöning-Stierand, K. ProteinsPlus: Interactive analysis of protein-ligand binding interfaces. Nucleic Acids Res. 2020. [CrossRef]

50. Adasme, M.F.; Linnemann, K.L.; Bolz, S.N.; Kaiser, F.; Salentin, S.; Haupt, V.J.; Schroeder, M. PLIP 2021: Expanding the scope of the protein-ligand interaction profiler to DNA and RNA. Nucleic Acids Res. 2021. [CrossRef] [PubMed]

51. Pettersen, E.F.; Goddard, T.D.; Huang, C.C.; Couch, G.S.; Greenblatt, D.M.; Meng, E.C.; Ferrin, T.E. UCSF Chimera?A visualization system for exploratory research and analysis. J. Comput. Chem. 2004, 25, 1605-1612. [CrossRef]

52. Kong, R.; Yang, G.; Xue, R.; Liu, M.; Wang, F.; Hu, J.; Guo, X.; Chang, S.; Ponty, Y. COVID-19 Docking Server: A meta server for docking small molecules, peptides and antibodies against potential targets of COVID-19. Bioinformatics 2020. [CrossRef]

53. Kong, R.; Wang, F.; Zhang, J.; Wang, F.; Chang, S. CoDockPP: A Multistage Approach for Global and Site-Specific Protein-Protein Docking. J. Chem. Inf. Modeling 2019, 59, 3556-3564. [CrossRef]

54. Li, H.; Leung, K.-S.; Wong, M.-H.; Ballester, P.J. Correcting the impact of docking pose generation error on binding affinity prediction. BMC Bioinform. 2016, 17. [CrossRef]

55. Rivero-Segura, N.A.; Gomez-Verjan, J.C. In Silico Screening of Natural Products Isolated from Mexican Herbal Medicines against COVID-19. Biomolecules 2021, 11, 216. [CrossRef]

56. Jin, Z.; Du, X.; Xu, Y.; Deng, Y.; Liu, M.; Zhao, Y.; Zhang, B.; Li, X.; Zhang, L.; Peng, C.; et al. Structure of Mpro from SARS-CoV-2 and discovery of its inhibitors. Nature 2020. [CrossRef]

57. Daina, A.; Michielin, O.; Zoete, V. SwissADME: A free web tool to evaluate pharmacokinetics, drug-likeness and medicinal chemistry friendliness of small molecules. Sci. Rep. 2017, 7, 1-13. [CrossRef]

58. Baell, J.B.; Holloway, G.A. New substructure filters for removal of pan assay interference compounds (PAINS) from screening libraries and for their exclusion in bioassays. J. Med. Chem. 2010, 53, 2719-2740. [CrossRef]

59. Zhang, L.; Lin, D.; Sun, X.; Curth, U.; Drosten, C.; Sauerhering, L.; Becker, S.; Rox, K.; Hilgenfeld, R. Crystal structure of SARS-CoV-2 main protease provides a basis for design of improved $\alpha$-ketoamide inhibitors. Science 2020, eabb3405. [CrossRef] [PubMed]

60. Mangum, E.M.; Graham, K.K. Lopinavir-Ritonavir: A New Protease Inhibitor. Pharmacotherapy 2001, 21, 1352-1363. [CrossRef]

61. Bharadwaj, S.; Azhar, E.I.; Kamal, M.A.; Bajrai, L.H.; Dubey, A.; Jha, K.; Yadava, U.; Kang, S.G.; Dwivedi, V.D. SARS-CoV-2 Mpro inhibitors: Identification of anti-SARS-CoV-2 Mpro compounds from FDA approved drugs. J. Biomol. Struct. Dyn. 2020, 1-16. [CrossRef]

62. Pojskic, L. Screening of preferential binding affinity of selected natural compounds to SARS-CoV-2 proteins using in silico methods. Eurasian J. Med. Oncol. 2020. [CrossRef]

63. Guevara-Figueroa, T.; Jiménez-Islas, H.; Reyes-Escogido, M.L.; Mortensen, A.G.; Laursen, B.B.; Lin, L.-W.; De León-Rodríguez, A.; Fomsgaard, I.S.; de la Rosa, A.P.B. Proximate composition, phenolic acids, and flavonoids characterization of commercial and wild nopal (Opuntia spp.). J. Food Compos. Anal. 2010, 23, 525-532. [CrossRef]

64. Ammar, I.; Ennouri, M.; Bouaziz, M.; Amira, A.B.; Attia, H. Phenolic profiles, phytchemicals and mineral content of decoction and infusion of Opuntia ficus-indica flowers. Plant Foods Hum. Nutr. 2015, 70, 388-394. [CrossRef]

65. Banerjee, R.; Perera, L.; Tillekeratne, L.M.V. Potential SARS-CoV-2 main protease inhibitors. Drug Discov. Today 2020. [CrossRef]

66. Singh, E.; Khan, R.J.; Jha, R.K.; Amera, G.M.; Jain, M.; Singh, R.P.; Muthukumaran, J.; Singh, A.K. A comprehensive review on promising anti-viral therapeutic candidates identified against main protease from SARS-CoV-2 through various computational methods. J. Genet. Eng. Biotechnol. 2020, 18, 1-12. [CrossRef] [PubMed] 
67. Sajid Jamal, O.M.; Alharbi, A.H.; Ahmad, V. Identification of doxorubicin as a potential therapeutic against SARS-CoV-2 (COVID-19) protease: A molecular docking and dynamics simulation studies. J. Biomol. Struct. Dyn. 2021, 1-15. [CrossRef] [PubMed]

68. Tariq, A.; Mateen, R.M.; Afzal, M.S.; Saleem, M. Paromomycin: A potential dual targeted drug effectively inhibits both spike (S1) and main protease of COVID-19. Int. J. Infect. Dis. 2020, 98, 166-175. [CrossRef] [PubMed]

69. Glaser, J.; Holzgrabe, U. Focus on PAINS: False friends in the quest for selective anti-protozoal lead structures from Nature? MedChem Comm 2016, 7, 214-223. [CrossRef]

70. Singab, A.N.B.; Youssef, D.T.; Noaman, E.; Kotb, S. Hepatoprotective effect of flavonol glycosides rich fraction from egyptianVicia calcarata desf. Against CCI 4-induced liver damage in rats. Arch. Pharmacal Res. 2005, 28, 791-798. [CrossRef] [PubMed]

71. Ho, L.-K.; Lin, W.-N. Quercetin 5, 4'-dimethyl Ether from Rhododendron ellipticum. Phytochemistry 1995, 39, $463-464$.

72. The China Medicinal Materials Group. Main Record of Resource of Chinese Material Medicine in China; Science Press: Beijing, Chain, 1994; p. 892.

73. Lambert, H.; Mohan, N.; Lee, T.-C. Ultrahigh binding affinity of a hydrocarbon guest inside cucurbit [7] uril enhanced by strong host-guest charge matching. Phys. Chem. Chem. Phys. 2019, 21, 14521-14529. [CrossRef] [PubMed] 